University of Nebraska - Lincoln

DigitalCommons@University of Nebraska - Lincoln

\title{
Cooperation and competition: nepotistic tolerance and intrasexual aggression in western bluebird winter groups
}

\author{
Janis L. Dickinson \\ Cornell Laboratory of Ornithology, jld84@cornell.edu \\ Melody Euaparadorn \\ U.S. Geological Survey, Hawaii Cooperative Studies Unit \\ Katherine Greenwald \\ The Ohio State University, katherine.greenwald@emich.edu \\ Chandreyee Mitra \\ University of Nebraska-Lincoln, chandreyee.mitra@gmail.com \\ Daizaburo Shizuka \\ University of Nebraska-Lincoln, dshizuka2@unl.edu
}

Follow this and additional works at: https://digitalcommons.unl.edu/biosciornithology

Part of the Poultry or Avian Science Commons

Dickinson, Janis L.; Euaparadorn, Melody; Greenwald, Katherine; Mitra, Chandreyee; and Shizuka, Daizaburo, "Cooperation and competition: nepotistic tolerance and intrasexual aggression in western bluebird winter groups" (2009). Papers in Ornithology. 88.

https://digitalcommons.unl.edu/biosciornithology/88

This Article is brought to you for free and open access by the Papers in the Biological Sciences at DigitalCommons@University of Nebraska - Lincoln. It has been accepted for inclusion in Papers in Ornithology by an authorized administrator of DigitalCommons@University of Nebraska - Lincoln. 


\title{
Cooperation and competition: nepotistic tolerance and intrasexual aggression in western bluebird winter groups
}

\author{
Janis L. Dickinson ${ }^{\mathrm{a}, *}$, Melody Euaparadorn ${ }^{\mathrm{b}}$, Katherine Greenwald ${ }^{\mathrm{c}}$, Chandreyee Mitra ${ }^{\mathrm{d}}$, \\ Daizaburo Shizuka ${ }^{\mathrm{e}}$ \\ a Department of Natural Resources, Cornell University and Cornell Laboratory of Ornithology \\ ${ }^{\mathrm{b}}$ U.S. Geological Survey, Hawaii Cooperative Studies Unit, Pacific Aquaculture and Coastal Resources Center, University of Hawaii at Hilo \\ ${ }^{\mathrm{c}}$ Department of Evolution, Ecology and Organismal Biology, The Ohio State University \\ ${ }^{\mathrm{d}}$ School of Biological Sciences, University of Nebraska-Lincoln \\ ${ }^{\mathrm{e}}$ Department of Ecology and Evolutionary Biology, University of California, Santa Cruz
}

\section{A R T I C L E I N F O}

\section{Article history:}

Received 30 April 2008

Initial acceptance 19 June 2008

Final acceptance 26 November 2008

Published online 4 February 2009

MS. number: A-8-00288R

\section{Keywords:}

cooperative breeding

group living

nepotism

sexual competition

Sialia mexicana

western bluebird

winter flock
Two hypothesized benefits of delayed dispersal are access to resources and prolonged brood care (or parental nepotism). Resource abundance (mistletoe wealth) is a key factor influencing whether sons stay home in western bluebirds, Sialia mexicana, but nepotism is also observed. Western bluebird sons commonly remain in their family groups throughout the winter, whereas daughters usually disperse before winter. Because pairing often takes place in winter groups, with newly formed pairs settling on exclusive all-purpose territories in spring, selection for sexual competition and nepotism co-occur and may simultaneously influence patterns of aggression within groups. We measured aggression at mealworm feeder stations, finding evidence of (1) intrasexual aggression against unrelated group members by experienced breeders of both sexes and (2) nepotism towards sons and daughters by experienced breeder females but not by experienced breeder males. Females showed much higher levels of aggression towards same-sex immigrants than males did. Experienced breeder males did not evict their sons from the natal territory, but they were 12 times more aggressive towards sons than breeder females were towards daughters. They were also equally aggressive towards sons and immigrant males, suggesting that local breeding competition and the benefits of intrasexual dominance counter the benefits of paternal nepotism towards sons.

(c) 2009 The Association for the Study of Animal Behaviour. Published by Elsevier Ltd. All rights reserved.
Cooperative kin groups typically form by delayed dispersal, when young prolong their attachment to their natal territory and to their parents beyond the usual interval to independence (Emlen 1982; Koenig et al. 1992; Ekman et al. 2004). In some cases, lifetime reproductive success of retained offspring exceeds that of individuals that have left their home territories, leading to the hypothesis that delayed dispersal occurs where home provides a safe haven (Ekman et al. 1999). Familiarity with the natal territory's foraging sites and shelters may increase survival, and staying home may allow offspring to queue for high-quality breeding vacancies (Kokko \& Ekman 2002) while avoiding potential energetic and predation costs of dispersal. These hypothesized advantages may be accentuated if the natal territory has abundant resources compared to other available sites (Dickinson \& McGowan 2005), and resource abundance, in turn, may reduce costs of nepotism if

\footnotetext{
* Correspondence: J. L. Dickinson, Department of Natural Resources, Cornell University and Cornell Laboratory of Ornithology, 159 Sapsucker Woods Road, Ithaca, New York 14850, U.S.A.

E-mail address: jld84@cornell.edu (J.L. Dickinson).
}

wealthier parents can better afford to share resources with offspring (Ekman \& Rosander 1992; Ekman et al. 2004).

In western bluebirds, Sialia mexicana, sons usually stay on their natal territories during winter, while daughters typically disperse and winter elsewhere (Kraaijeveld \& Dickinson 2001). If they do stay home for winter, daughters tend to disperse away from the natal territory in spring, while sons tend to breed near home. The general pattern of female-biased dispersal, where females travel further to breed than males, is common in passerine birds. The most widely accepted explanation for this pattern is that costs of incest combine with a sexual asymmetry in the benefits of remaining home to favour greater philopatry of one sex over the other, generally producing female-biased dispersal in passerine birds and male-biased dispersal in nonhuman mammals (Greenwood \& Harvey 1982; Harvey \& Ralls 1986; Koenig et al. 1999).

Delayed dispersal creates opportunities for kin-directed social behaviours (Ekman et al. 2004). In western bluebirds, males commonly delay dispersal, but only occasionally help at the nest. Cooperative family groups form in autumn and commonly persist through the winter, usually breaking up in spring when yearling 
birds disperse to breed as socially monogamous pairs on exclusive territories (Dickinson et al. 1996; Kraaijeveld \& Dickinson 2001). Yearling males often pair with immigrant females that have joined their winter family groups, and then settle near home in spring, sometimes reuniting territories with their parents' territories the following winter. This close proximity leads to prolonged and fluid relationships among kin that involve a complex blend of cooperation (e.g. helping, vigilance, assistance with territory defence) and competition, particularly with respect to mating with females, which are in short supply (Dickinson 2004b).

In central coastal California, familial mistletoe wealth is critical to delayed dispersal. In a mistletoe removal experiment, sons left their parents and their natal territory to disperse elsewhere when mistletoe volume was experimentally reduced by half (Dickinson \& McGowan 2005). In contrast, dispersal of daughters was not discernibly affected by resource reduction, implying that factors other than resource abundance may influence delayed dispersal of females. Even though reducing resource wealth caused sons to leave their parents, which still remained on territory for winter, the experiment did not falsify parental nepotism as an important factor in delayed dispersal, because nepotistic food sharing should vary according to resource abundance. The costs and benefits are influenced by the severity of competition between parents and offspring for winter food (Ekman \& Rosander 1992) as well as future competition for territories and mates.

Nepotism is expressed as feeding tolerance (Sklepkovych 1997), parental vigilance (Griesser 2003), mobbing (Griesser \& Ekman 2005) and alarm calling (Griesser \& Ekman 2004) in a Swedish population of the Siberian jay, Perisoreus infaustus, in which offspring delay dispersal for up to 3 years, but never help at the nest. The primary finding in the jay system is that nepotism is the key to delayed dispersal (Ekman \& Griesser 2002), which in turn is associated with increased survival among retained offspring (Griesser et al. 2006). While Griesser \& Ekman (2004) noted differences in nepotistic tendencies based on parent sex, their focus was largely on investigating the extent and fitness consequences of nepotism. The question of whether parental nepotism is influenced by intrasexual competition remains unexplored.

Given that group living almost always involves both cooperative and competitive interests, it is reasonable to expect that the costs and benefits of nepotism will differ substantially depending upon both parental and offspring sex. This is particularly true in western bluebirds since only sons help at the nest as yearlings and, when they do not help, they typically settle to breed near home. Even when daughters stay the winter, which is not common, they tend to leave the natal area in early spring and never help at the nest as adults (Dickinson et al. 1996; Kraaijeveld \& Dickinson 2001). It is important to investigate nepotism on a sex-by-sex basis to rule out the possibility that opposing sex-specific patterns of aggression mask important trends. Western bluebirds, which can be sexed by plumage in the nest, are aggressive towards extragroup intruders. Group members of all ages and both sexes engage in cooperative defence of the winter territory (Kraaijeveld \& Dickinson 2001). Patterns of aggression against extragroup intruders are consistent with the hypothesis that sexual competition is an important driver of winter social interactions (Kleiber et al. 2007). If patterns of extragroup competition are governed by sexual competition, interactions within winter groups may also be influenced by sexual competition.

In this study we examined aggression at mealworm feeder stations placed on western bluebird territories in the winters of 2001-2004 to quantify patterns of intragroup aggression and nepotism in a competitive feeding situation. We made several predictions regarding interactions in this situation. First, we predicted that parents would show nepotism, measured as patterns of aggression that favour their offspring over immigrant birds of the same sex and age as their offspring. Second, as pairs form in winter groups, we predicted that parents would be more aggressive towards same-sex immigrants than towards opposite-sex immigrants because of the greater potential for social mate competition with immigrants of the same sex. Third, we predicted that sexual competition should lead to less nepotism between fathers and sons than between mothers and daughters, because daughters tend to disperse quite far after winter whereas sons compete locally for mates (Kraaijeveld \& Dickinson 2001). Because western bluebirds show incest avoidance, sons are not usually in direct competition with their fathers for social mates as long as their mother is still present; however, because annual mortality is in the range of $50 \%$, direct competition between fathers and sons may be common enough to drive patterns of aggression.

\section{METHODS}

\section{Study Population}

Western bluebirds were colour-banded and monitored from 1983 to 2008 (Hastings Reservation/Oak Ridge Ranch) and from 2001 to 2007 (Rana Creek Ranch). In spring, nestlings and adults were trapped at the nest, and in winter, they were trapped on the roost or captured in mist nets and potter's traps at mealworm feeder stations (see below for details) or water troughs. We based our assessment of group size and composition on three to four $1 \mathrm{~h}$ winter censuses per month during October-February as well as incidental identifications gleaned during territory mapping, capture and behavioural studies. Winter groups were stable by October and while birds displaced each other and engaged in countersinging, groups were very cohesive, roosting together, foraging together and arriving on or departing from their territories as a group.

In this study, we examined interactions among 'experienced breeder' males or females and two classes of first-winter or hatchyear (HY) birds that were nestlings the prior spring: (1) immigrant hatch-year (HY) birds and (2) the breeders' sons or daughters. As our goal was to compare parents' treatment of their own offspring with their treatment of unrelated young of the year, we attempted to balance our sample sizes by choosing to observe a surplus of groups with immigrant $\mathrm{HY}$ males and stay-at-home female offspring, which are more rare than stay-at-home male offspring and immigrant HY females (Kraaijeveld \& Dickinson 2001).

\section{Observation of Aggression at Feeder Stations}

During the three winter seasons from 2002 to 2005, we monitored aggression using direct observation and videotaped watches initiated 1-3 months after winter group formation (1 November to 15 January). This bioassay was designed to examine patterns of within-group aggression (and its opposite, tolerance) within the context of competition for a concentrated food supply. While competitive interactions and dominance behaviour can be observed during natural conditions, the interactions are infrequent. To observe sufficient interactions to detect differential patterns of aggression among dyad types, we provided a concentrated mealworm source that was sufficient in quantity to last the entire observation period, allowing us to identify individuals based on colour bands. This provided us with a bioassay to compare the intensity of aggression between related and unrelated dyads within the groups.

We constructed square $\left(1600 \mathrm{~cm}^{2}\right)$ platform feeder stations of 0.5 inch $(1.27 \mathrm{~cm})$ rough plywood and placed them on metal fence posts. The platform size was selected to be large enough to allow 
8-10 birds to occupy the platform simultaneously. We attached a plastic weighing dish (Fisher Catalog No. 2-202D) to the feeder tray with Velcro and filled it with mealworms to train birds to the feeder station. Once the birds were trained, we measured 10-30 g of mealworms (depending on group size) and placed them into the feeder prior to starting a watch. We observed the feeder station for 1-2 $\mathrm{h}$ after arrival of the birds using a combination of High-8 videorecording and direct observation through spotting scopes. We distinguished individual birds by colour bands and when the identity of a bird was ambiguous, we excluded it from analysis. We also only included cases where both the arrival time and the departure time were recorded for both birds in a dyad. We collected a mean \pm SE of $498 \pm 45$ min of observation per group (range 60$945 \mathrm{~min}$ ) for a total of $215 \mathrm{~h}$ of field observations on 26 groups. The number and duration of observation periods varied with group size (3-11 individuals) because larger groups necessitated longer periods of observation to capture data on all dyads of experienced breeders and first-winter birds.

We determined aggression based upon operational definitions specified prior to analysis. Bird A was aggressive to bird B when it engaged in the following behaviours: (1) lunging, in which bird A moved (walked or hopped) towards bird B, causing bird B to walk, hop, or fly away; (2) displacement, in which bird A landed within $10 \mathrm{~cm}$ of bird B with the result that bird B immediately left the feeding platform or hopped more than $10 \mathrm{~cm}$ away; (3) chases, when bird $B$ approached the feeding platform within $0.5 \mathrm{~m}$ and was chased by bird A within $2 \mathrm{~s}$; and (4) aborted landings, where bird $B$ approached the platform within $10 \mathrm{~cm}$ and bird A lunged or hopped towards B, such that B did not land. Although all of these behaviours were observed, the most common were lunging and displacement (93\% of 95 observations tallied to examine the frequency of each of the four types of aggression). Chasing, which was the most aggressive of these four behaviours, was rare (3\% of observations). Aggression of first-winter individuals towards experienced breeders was extremely rare and not included in the analysis.

Our index of aggression was the proportion of times that the experienced breeder was aggressive towards the first-winter bird for all occasions when they were on the feeder station simultaneously. Regardless of the presence of other birds on the feeder, we refer to each dyad's simultaneous occupancy of the feeder station as an 'interaction' for that dyad. Each interaction for a particular dyad began when the second bird landed, and terminated when one of the pair left the feeder. To distinguish departures from hops, we designated an individual as having left the feeder when it flew more than $0.5 \mathrm{~m}$ from the feeder or landed on another substrate, including the ground or a nearby branch. If the bird then returned to the feeder while the first bird was still present, a new interaction began. In contrast, if one of a dyad of birds left the feeder and flew or hovered, landing again on the feeder without moving more than $0.5 \mathrm{~m}$ away, we called this behaviour a 'hop' and the interaction continued.

We gathered data on nepotism for 26 groups over a 3-year period in the winters beginning in 2002 and ending in 2005. Each dyad used in the analysis consisted of one experienced breeder and one first-winter individual (including HY offspring and unrelated HY birds that joined the groups). The data set included 111 unique dyads of birds broken down as follows: 14 mother-son, 10 motherdaughter, 16 mother-unrelated HY female, 11 mother-unrelated HY male, 20 father-son, 11 father-daughter, 18 father-unrelated HY female, 10 father-unrelated HY male, with 'father' and 'mother' representing the experienced breeder male and female from the prior spring. We only included dyads with at least six interactions. Unrelated females tended to be immigrants from off the study area and in all cases they were unrelated to the 'parents' $(r<0.25)$.

\section{Statistical Analysis}

Statistical analysis was conducted in SPSS V15.0 (SPSS, Chicago, IL, U.S.A.). Means are presented \pm SE. Indexes and ratios were angularly transformed for analysis. Initially, models included group size as a covariate and year as a random factor (GLMM) along with the fixed factors related to the hypothesis tests (e.g. offspring versus unrelated immigrant; same versus opposite sex; sex of recipient and aggressor). Year and group size effects were not statistically significant, so these variables were omitted from the analyses after all nonsignificant interactions were removed in a backward stepwise fashion (by $P$ value).

\section{RESULTS}

\section{Evidence for Both Sexual Competition and Nepotism in Winter Groups}

Both nepotism and sexual competition explained patterns of aggression by experienced breeders towards young of the year in their winter groups (Table 1). Experienced breeders were more aggressive towards same-sex individuals than towards oppositesex individuals $\left(F_{1,107}=29.6, P<0.001\right)$ and they were also more aggressive towards unrelated first-winter birds than they were towards their own first-winter offspring $\left(F_{1,107}=19.5, P<0.001\right)$. Furthermore, the interaction between nepotism (parent-offspring or unrelated dyads) and sexual competition (same-sex or oppositesex dyads of unrelated birds) was statistically significant $\left(F_{1,107}=6.0, P=0.016\right)$.

\section{Sexual Variation in Patterns of Nepotism in Winter Groups}

As prior studies have not considered sexual variation in patterns of nepotism, we subdivided our data to examine the importance of the sex of the aggressor and the sex of the recipient of aggression. Birds that bred the prior spring were more aggressive to unrelated first-winter birds than to their own retained offspring in a GLM that included as fixed factors the sex of the experienced breeders, the sex of the HY bird that was the target of aggression, and whether or not the HY bird was an offspring (Table 2). This result was statistically significant in spite of significant two-way and three-way interactions among all three explanatory variables. Because of significant interactions between sex of experienced breeder, sex of first-winter bird, and the relationship between the two, we parsed the data to examine the interaction of sex with nepotism.

In a more refined analysis, female parents were nepotistic, but male parents were not. Female parents were more aggressive to first-winter immigrants of both sexes than to their own sons and daughters (GLM: immigrants versus sons: $F_{1,25}=3336, P=0.01$; immigrants versus daughters: $F_{1,27}=22.6, P<0.001$; Fig. 1 ). In contrast, male parents did not show statistically significant patterns of feeding tolerance (reduced aggression) consistent with nepotism (GLM: immigrants versus sons: $F_{1,30}=0.82, P=0.50$; immigrants versus daughters: $F_{1,29}=0.16, P=0.69$; Fig. 1 ). The interaction plot

Table 1

Mean \pm SE $(N)$ aggression index of experienced western bluebird breeders towards hatch-year birds*

\begin{tabular}{lll}
\hline Comparison (A vs B) & A & B \\
\hline Recipient offspring vs nonrelative $\dagger$ & $0.07 \pm 0.01(55)$ & $0.19 \pm 0.04(56)$ \\
Aggressor and recipient, same vs opposite sex $\dagger$ & $0.19 \pm 0.04(57)$ & $0.07 \pm 0.01(54)$
\end{tabular}

* Proportion of times that the experienced breeder was aggressive towards the hatch-year bird out of all occasions when the two were on the feeder together.

$\dagger$ See statistical test results in text. 
Table 2

Results of general linear model for western bluebirds examining the aggression index as a function of breeder sex, first-winter bird sex, and whether the first-winter bird was an offspring of the experienced breeder or an immigrant in the group [offspring (yes/no)]

\begin{tabular}{llrr}
\hline Source & $d f$ & \multicolumn{1}{l}{$F$} & \multicolumn{1}{l}{$P$} \\
\hline Corrected model & 7 & 7.14 & $<0.001$ \\
Intercept & 1 & 88.11 & $<0.001$ \\
Sex of experienced breeder (aggressor) & 1 & 0.55 & 0.460 \\
Sex of first-winter bird (victim) & 1 & 0.06 & 0.807 \\
Offspring of experienced breeder (yes/no) & 1 & 12.90 & $0.001^{*}$ \\
Sex of experienced breeder $\times$ sex of first-winter bird & 1 & 6.90 & $0.010^{*}$ \\
Sex of experienced breeder $\times$ offspring (yes/no) & 1 & 13.06 & $0.001^{*}$ \\
Sex of first-winter bird $\times$ offspring (yes/no) & 1 & 4.10 & $0.045^{*}$ \\
Sex of experienced breeder $\times$ & 1 & 6.59 & $0.012^{*}$ \\
$\quad$ sex of first-winter bird $\times$ offspring (yes/no) & & & \\
Error & 103 & & \\
Total & 111 & & \\
\hline
\end{tabular}

* Denotes statistical significance at alpha $=0.05$.

in Fig. 2a is drawn from the GLM in Table 2, and shows that experienced breeder females were less aggressive to their own offspring than to unrelated first-winter birds, whereas experienced breeder males were equally aggressive to related and unrelated birds.

Group size varied from 3 to $11(6.1 \pm 0.5$, median $=5.5)$. If aggression increases with group size and presence of unrelated, immigrant HY birds is more likely in larger groups, what appears to be nepotism could be a spurious result driven by group size effects. We tested this possibility by analysing female nepotism using matched pairs of mother-daughter and mother-immigrant HY female dyads within groups. A paired $t$ test on the arcsine squareroot of the aggression indexes supported the prediction of nepotism ( 8 within-group dyads of daughters and unrelated HY females: $0.09 \pm 0.06$ versus $\left.0.63 \pm 0.15 ; t_{7}=3.03, P=0.019\right)$. Finally, we examined the relationship between levels of aggression and group size to see whether there was a possible bias and found no correlation between aggression index and group size for any of the eight dyad categories (experienced breeder males and females with male and female offspring or unrelated HY birds of either sex; 8 correlations: $-0.54 \geq r \leq 0.15, P>0.09$ ).

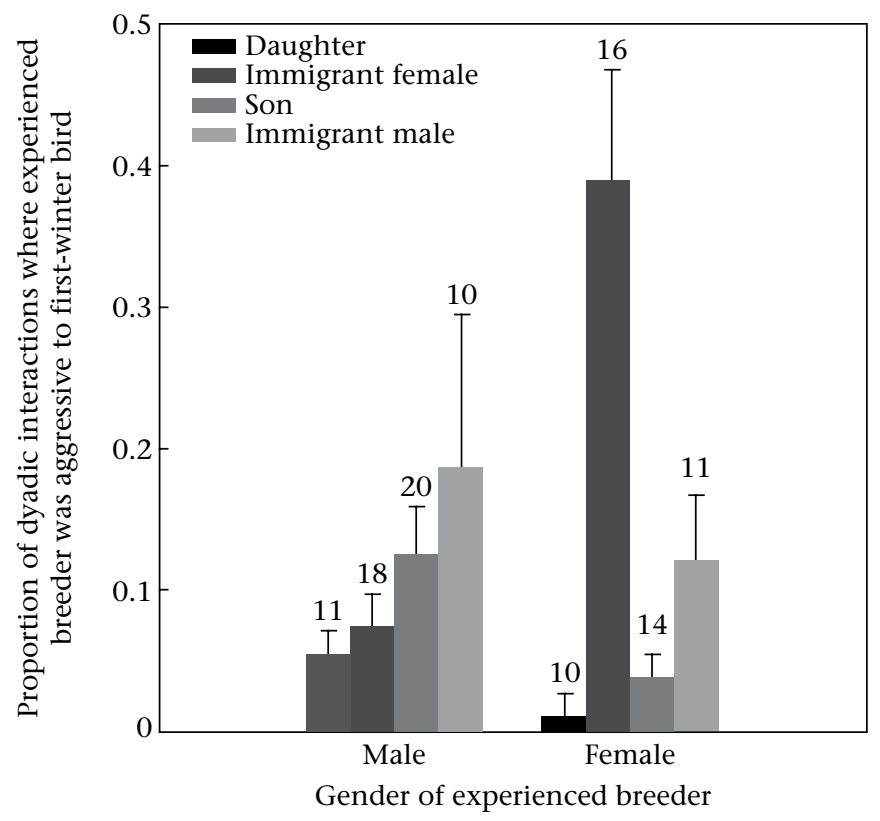

Figure 1. Aggression index for experienced breeders towards first-winter western bluebirds in their winter groups, including daughters, immigrant females, sons and immigrant males.

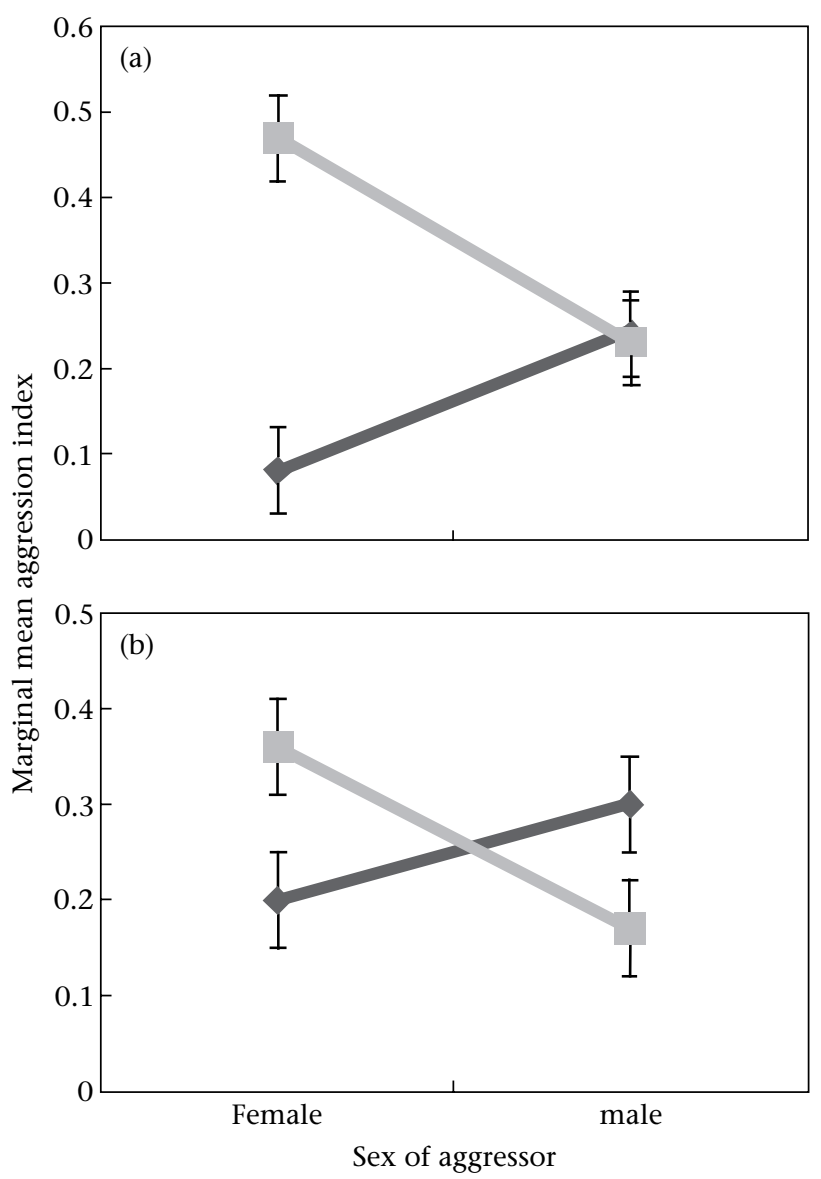

Figure 2. Plots of the marginal mean aggression indexes comparing (a) interactions between sex of experienced breeder and aggression towards same-sex offspring (black diamond) versus immigrants (grey square) and (b) interaction between sex of aggressor and aggression towards male (black diamond) versus female (grey square) first-winter (HY) birds. The marginal mean of one factor is the mean for that factor averaged across all levels of the other factors.

\section{Predictions Based on Local Mate Competition}

Based on the GLM in Table 2, the interaction plot in Fig. 2b shows that both males and females were more aggressive towards samesex individuals than they were towards opposite-sex individuals in winter. If local mate competition between parents and offspring influences patterns of tolerance and aggression within winter groups, then adult males should be more aggressive to sons than females are to daughters. Sons stay the winter and breed locally, whereas even when daughters remain on the family territory for the winter, they disperse quite far to breed in spring (Kraaijeveld \& Dickinson 2001). Male aggression towards sons was approximately 12 times higher than female aggression towards daughters (12.5 versus $1.1 \%$ of interactions where parent and same-sex offspring were together on the feeder; $F_{1,109}=3.23, P=0.043$ ).

\section{DISCUSSION}

Our observations of intragroup aggression within a feeding context support the hypothesis of nepotism for female, but not male, parents. Female parents were nepotistic to both first-winter daughters and sons relative to unrelated first-winter birds that joined their group in early autumn. The simple model with sex of aggressor versus recipient (opposite versus same), status of the recipient of aggression (immigrant versus offspring), and the 
significant two-way interaction, sex * status, explained $25 \%$ of the variance in aggression. Not included in the simple model was an analysis by sex of the experienced breeder, specifically asking how males and females differed in the extent of their nepotism. Analysed separately, experienced breeder females were less aggressive to their offspring than to nonrelatives, whereas experienced breeder males did not discriminate. These results were consistent with the patterns shown in the interaction plots, showing that nepotism is a sex-specific trait in the western bluebird (Fig. 2a, b).

Western bluebirds mainly live in groups outside the breeding season, and sexual competition plays a significant role in territorial aggression against caged intruders in winter (Kleiber et al. 2007). Sexual competition also predicted the patterns of aggression within winter groups in this study, indicating that mate selection may be a gradual process that occurs through repeated within-group interaction throughout the nonbreeding season, rather than an abrupt process that occurs in spring. This idea is also supported by the observation that many retained sons (57-61\%) pair with females that join their winter group (Kraaijeveld \& Dickinson 2001).

Experienced breeders, both male and female, were more tolerant of opposite-sex immigrants than they were of same-sex immigrants, indicating that sexual competition is important in shaping within-group tolerance and aggression. While incest is rare in our study population, fathers sometimes lose mates over the winter because annual adult mortality is about 50\% (Dickinson et al. 1996). In this event they will compete with males within the group, including their sons, for remaining unrelated females. Even during the breeding season, after settlement, fathers potentially compete with sons, as in one case, where a widowed father sang to, approached and eventually usurped his son's mate from an adjacent territory over a 3-day period, after which his son attracted a new, unbanded female (J. L. Dickinson, unpublished data). Although sons are competitors with their fathers, they are also offspring, whose survival and reproductive success adds to the fitness of both their parents. Why are fathers not more tolerant of their sons than of unrelated males? Aggression towards sons may manifest as dominance, which influences competition for space, mates and fertilizations in spring and over the long term.

Paternal dominance is particularly important if the mother dies, but it may also be important within the context of extrapair fertilizations the following spring. Fathers sometimes copulate with their sons' mates during mate-guarding and male detention trials (Dickinson \& Leonard 1996; Dickinson 1997), and there is a tendency for females to be more receptive to extrapair males that are older than their mates (Dickinson 2001); however, we do not yet know the frequency with which fathers sire offspring with mates of nearby sons. Aggression towards sons may increase the father's access to extrapair females, including the son's mate, as fertilization partners. The costs of aggression for sons are unknown, but may include reduced survival and reproductive success, especially if the capacity to obtain a territory, mate or winter food is reduced.

Parents are hypothesized to concede food to offspring where the benefits of food sharing outweigh the costs (Ekman \& Rosander 1992; Ekman et al. 2004). The combination of local mate competition among males, cooperation and the potential for long-term impacts of dominance-mediated social interactions in western bluebirds provide an interesting example of the complex nature of cooperation and conflict in social groups comprising both kin and nonkin. While prior studies of Siberian jays indicate that nepotism is important in both food-sharing and alarm-calling contexts, a potential role for sexual competition remains unexplored, because analyses did not include information on the sex of the young birds in the group (Griesser 2003; Griesser \& Ekman 2004,
2005). Sexual competition affects breeding outcomes through winter dominance hierarchies and mate choice in chickadees and other flocking birds (Otter et al. 1999); as this study shows, these factors may also be important in winter groups of close kin. In western bluebirds both intergroup and intragroup aggression are modulated by sexual competition, with individuals being more aggressive towards same-sex conspecifics than they are towards opposite-sex conspecifics, even in mid-winter. Furthermore, it may be argued that males, which face a shortage of mates (Dickinson 2004a), experience trade-offs between nepotism and dominance towards their sons. This alone could cause males to behave more aggressively than females to members of the same sex.

Consistent with local mate competition, we found that intrasexual aggression of experienced breeders towards same-sex offspring differed for males and females, with experienced breeder males showing stronger aggression towards sons than experienced breeder females showed towards daughters. This difference was predicted based upon prior work showing that sons compete locally for mates while the smaller percentage of daughters staying the winter typically disperse elsewhere to breed (Kraaijeveld \& Dickinson 2001). Local mate competition may be responsible for the significant interaction between nepotism and sexual competition. In other words, if dominance determines the outcome of local mate competition, this may favour fathers being equally aggressive to sons and unrelated males.

Teasing apart the dynamics of group-living animals in winter, including parsing out effects due to kinship and sexual competition, stands to contribute much to our understanding of the functional significance of traits and behaviours of cooperative breeders that we currently understand only within the context of the breeding season (Ekman et al. 2004; Covas \& Griesser 2007; Kleiber et al. 2007). Furthermore, as future roles and options are likely to depend on the outcome of dominance interactions in winter for year-round residents (Otter et al. 1999), breeding season studies may fall short of understanding the underlying social dynamics in cooperative breeders, particularly those interactions that determine who stays, who survives and reproduces, who helps, and ultimately, how the frequencies of these complex behaviours are regulated. Even in the days of 'molecular behaviour', it seems critical to retain an awareness of the importance of behavioural dynamics for understanding how selection shapes patterns of inter- and intragroup interactions and how these relate to fitness.

\section{Acknowledgments}

We are grateful to Elise Ferree, the editors, and the referees, Cas Eikenaar and Michael Griesser, for their careful reading of and helpful comments on the manuscript. We also thank the staff and leadership of the Museum of Vertebrate Zoology and Hastings Reserve for logistical support for this study and landowners at Rana Creek Ranch and Oak Ridge Ranch for access to their property. Many field interns helped to keep the population banded over the years, leading to this study. Support came from National Science Foundation Research Grants IOS-0637138 and IOS-0718416 to J.L.D.

\section{References}

Covas, R. \& Griesser, M. 2007. Life history and the evolution of family living in birds. Proceedings of the Royal Society of London, Series B, 274, 1349-1357.

Dickinson, J. 1997. Male detention affects extra-pair copulation frequency and pair behaviour in western bluebirds. Animal Behaviour, 53, 561-571.

Dickinson, J. L. 2001. Extrapair copulations in western bluebirds: female receptivity depends on male age. Behavioral Ecology and Sociobiology, 50, 423-429.

Dickinson, J. 2004a. Facultative sex ratio adjustment by western bluebird mothers with stay-at-home helpers-at-the-nest. Animal Behaviour, 68, 373-380. 
Dickinson, J. L. 2004b. Local breeding competition and a female shortage explain helping behavior and facultative sex ratio adjustment in western bluebirds. Animal Behaviour, 68, 233-238.

Dickinson, J. \& Leonard, M. L. 1996. Mate attendance and copulatory behavior in western bluebirds. Animal Behaviour, 52, 981-992.

Dickinson, J. L. \& McGowan, A. 2005. Resource wealth drives family group living in western bluebirds. Proceedings of the Royal Society of London, Series B, 272, 2423-2428.

Dickinson, J. L., Koenig, W. D. \& Pitelka, F. A. 1996. Fitness consequences of helping behavior in the western bluebird. Behavioral Ecology, 7, 168-177.

Ekman, J. \& Griesser, M. 2002. Why offspring delay dispersal: experimental evidence for a role of parental tolerance. Proceedings of the Royal Society of London, Series B, 269, 1709-1714.

Ekman, J. \& Rosander, B. 1992. Survival enhancement through food sharing: a means for parental control of natal dispersal. Theoretical Population Biology, 42, 117-129.

Ekman, J., Bylin, A. \& Tegelström, H. 1999. Increased lifetime reproductive success for Siberian jay, Perisoreus infaustus, males with delayed dispersal. Proceedings of the Royal Society of London, Series B, 266, 911-915.

Ekman, J., Dickinson, J. L., Hatchwell, B. J. \& Griesser, M. 2004. Delayed dispersal. In: Evolution and Ecology of Cooperative Breeding in Birds (Ed. by W. D. Koenig \& J. L. Dickinson), pp. 35-47. Cambridge: Cambridge University Press.

Emlen, S. T. 1982. The evolution of helping. I. An ecological constraints model. American Naturalist, 119, 29-39.

Greenwood, P. J. \& Harvey, P. H. 1982. The natal and breeding dispersal of birds. Annual Review of Ecology and Systematics, 13, 1-21.

Griesser, M. 2003. Nepotistic vigilance behaviour in Siberian jay parents. Behavioral Ecology, 14, 246-250.
Griesser, M. \& Ekman, J. 2004. Nepotistic alarm calling in the Siberian jay, Perisoreus infaustus. Animal Behaviour, 67, 933-939.

Griesser, M. \& Ekman, J. 2005. Nepotistic mobbing behaviour in the Siberian jay, Perisoreus infaustus. Animal Behaviour, 69, 345-352.

Griesser, M., Nystrand, M. \& Ekman, J. 2006. Reduced mortality selects for social cohesion in a social species. Proceedings of the Royal Society of London, Series B, 273, 1881-1886.

Harvey, P. H. \& Ralls, K. 1986. Do animals avoid incest? Nature, 320, 575-576.

Kleiber, D., Kyle, K., Rockwell, S. \& Dickinson, J. 2007. Sexual competition explains patterns of individual investment in territorial aggression in western bluebird winter groups. Animal Behaviour, 73, 763-770.

Koenig, W. D., Pitelka, F. A., Carmen, W. J., Mumme, R. L. \& Stanback, M. T. 1992 The evolution of delayed dispersal in cooperative breeders. Quarterly Review of Biology, 67, 111-150.

Koenig, W. D., Stanback, M. T. \& Haydock, J. 1999. Demographic consequences of incest avoidance in the cooperatively breeding acorn woodpecker. Animal Behaviour, 57, 1287-1293.

Kokko, H. \& Ekman, J. 2002. Delayed dispersal as a route to breeding: territoria inheritance, 'safe havens' and ecological constraints. American Naturalist, 160, 468-484.

Kraaijeveld, K. \& Dickinson, J. L. 2001. Family-based winter territoriality in western bluebirds: the structure and dynamics of winter groups. Animal Behaviour, 61, 109-117.

Otter, K., Ramsay, S. M. \& Ratcliff, L. 1999. Enhanced reproductive success of female black-capped chickadees mated to high-ranking males. Auk, 116, 345-354.

Sklepkovych, B. O. 1997. The influence of kinship on foraging competition in Siberian jays. Behavioral Ecology and Sociobiology, 40, 287-296. 